2. Количественные оценки критического числа Маха позволяют сделать вывод о неизбежности перехода неустойчивого самоускоряющегося процесса горения в развитую дефлаграцию или детонацию, т.е. во взрывной процесс. Предотвращение этого перехода возможно либо за счет внешних причин, не учтенных в задаче о внутренней устойчивости (внешние стабилизирующие факторы, различные энергетические потери в процессе горения, гашение пламени), либо в том случае, когда процесс автотурбулизации и самоускорения пламени сам Iю себе достаточно «медленный» и длина преддетонационного участка превышает длину канала или трубы, заполненных горючей средой (иначе говоря, когда выгорание происходит до перехода горения во взрыв).

3. Количественные оценки критического числа Маха позволяют также в определенной степени оценить какой именно взрывной процесс - дефлаграционный или детонационный - имеет место в результате развития неустойчивости, автотурбулизации и самоускорения пламени. Если $M_{1 \kappa p} \leq 0,15$, то взрывной процесс носит очевидно дефлаграционный характер.

4. Следует признать принципиально возможным недопущение перехода горения во взрыв даже на стадии автотубулизации пламени и его самоускорения.

Литература

1. Маркштейн Дж. Г. Нестационарное распространение пламени - М: Мир, 1968. - 440 с.

2. ІІетинков Е.С. Физика горения газов. - М: Наука, 1965. - 739 с.

3. ІІелкин К.И., Тропин Я.К. Газодинамика горения. - М.: Изд-во АН СССР.- $1963-256$ с.

4. Бесчастнов М.В. ІІромышленные взрывы. Оценка и предупреждение. - М.:Химия, 1991. - 432 с.

5. Взрывные явления. Оценка и последствия: В 2-х кн. Кн.1 /У. Бейкер, П. Кокс, П. Уэстайн и др. - М: Мир, 1986. $-319 \mathrm{c}$.

6. Васильев Я.Я., Семенов Л.И. Взрывобезопасность на предприятиях по хранению и переработке зерна. М.: Колос.- 1983. - 224c.

7. Асланов С.К., Волков В.Э. Интегральный метод анализа устойчивости ламинарного пламени. - Физика горения и взрыва, 1991, №5. - C. 160-166.

8. Aslanov S., Volkov V. On the Instability and Cell Structure of Flames. - Archivum combustionis, 1992, Vol.12, Nr. 1-4. - P. 81-90.

9. Волков В.Э., Рыбина О Б. Об устойчивости плоской стационарной волны медленного горения в сжимаемой среде. - Дисперсные системы. XXI научная конференция стран СНГ 20-24 сентября 2004 г., Одесса. Тезисы докладов. - Одесса: "Астропринт", 2004. - С. 75-76.

10. Ландау Л.Д., Лифшиц Е.М. Теоретическая физика. В 10 т.: Т. VI. Гидродинамика. - М.: Наука. Гл. ред. физ.-мат. лит.- 1986. - 736 с.

11. Овсянников Л.В. Лекции по основам газовой динамики. - М: Гл. ред. Физ.-мат. лит.- 1981 - 368 с.

12. Черный Г.Г. Газовая динамика. - М.: Наука. Гл. ред. физ.-мат. лит.- 1988. - 424 с.

13. І уссак Л.А., Спринцина Е.Н., Пелкин К.И. Исследование устойчивости фронта нормального пламени Физика горения и взрыва, 1968. - Т. 4, №3. - С. 358-366.

14. Волков В.Э. Развитие неустойчивости сферических пјамен - Зернові продукти і комбюкорми, 2008. - №2, червень 2008. - С. 51-54.

УДК 658.621 .798 .006 .5

\title{
ЭФФЕКТИВНЫЕ НАПРАВЛЕНИЯ ИННОВАЦИОННОГО РАЗВИТИЯ КОМПЛЕКСНО-МЕХАНИЗИРОВАННЫХ И АВТОМАТИЗИРОВАННЫХ ТСС
}

\author{
Жуковский Э.И., д.-р. техн. наук, профессор, Чабаров В.А., канд. техн. наук, доцент \\ Одесская нашиональная академия пишевых технологий, Одесса
}

ІІредложена фасетная ктассификация современных складов. Рассмотрены суцествуюице направления развития комплексно-иеханизированных и автолатизированных транспортно-складских систеи и проведен выбор эффективного варианта ТСС.

A facel classification of modern warehouses. The existing areas of development, highly mechanized and automated transport and storage systems, and the choice of the effective variant of TSS.

Ключевые слова: инновация, фассетная классификация, складская система, инвестиционный проект, стеллаж, карно-штучные грузы, способ хранения грузов, грузопоток, чистый денежный поток. 
В период экономического кризиса и сокращения объемов финансовых ресурсов важно классифицировать, какой объект на предприятии пищевой промышленности необходимо подвергнуть инновации. Затем следует рассмотреть эффективные проекты инновационного развития

Многообразие складов в отраслях АПК по назначению, характеру и условиям функционирования не дает возможности их классифицировать по одному или двум признакам. Классификационными признаками, по которым из существующего множества ТСС (транспортно-складские системы) выделяются подмножества, являются принадлежность к сфере деятельности, назначение склада, вид хранимых грузов. Однако приведенные иерархические классификации складов не позволяют во всей полноте отразить сложность складских объектов.

Практика проектирования современных ТСС показывает, что для принятия основных проектных решений необходима дальнейшая детализация в классификации складов и в первую очередь как систем массового обслуживания (СМО) грузов [1].

Структурно ТСС состоят из трех зон: приемки (приемная экспедиция), хранения и отпуска (отпускная экспедиция).

Свободной от ограничений традиционной классификации складов, обусловленной иерархической связью типа класс - подкласс и т.д., является фасетная классификация. Сущность ее состоит в распределении объектов по однородным взаимоисключаюцим фасетам, каждый из которых получен делением классифицируемого множества на основании одной характеристики деления. Фасетный анализ, устанавливаюший основные характеристики деления или категории, является основным процессом при построении фасетной классификации; в основу ее положены два принципа:

функциональный - систематизирующий склады в зависимости от направления деятельности, ведомственной принадлежности, назначения, т.е. основных выполняемых такими объектами функций;

структурный - отражающий структуру, параметры и внешние воздействия, определяющие существенные Іризнаки склада и механизм его работы.

В соответствии с первым принципом классификации можно образовать следующую фасетную формулу

принадлежность к сфере деятельности - $\mathrm{F}_{1}$;

ведомственная принадлежность $-\mathrm{F}_{2}$;

назначение склада $-\mathrm{F}_{3}$;

вид хранимой продукции $-\mathrm{F}_{4}$;

Признаки внутри каждого фасета определяются сушествующими иерархическими классификациями или существующим делением понятия:

\begin{tabular}{|c|c|}
\hline $\mathrm{F}_{1}$ & $F_{2}$ \\
\hline 1. ІІроизводственные склады $\mathrm{F}_{11}$ & 1. Склады отраслевые $\mathrm{F}_{21}$ \\
\hline 2. Склады снабжения $F_{12}$ & \multirow{2}{*}{$\begin{array}{l}\text { 10. Склады предприятий перерабатывающих } \\
\text { отраслей Агропрома } \mathrm{F}_{210}\end{array}$} \\
\hline 3. Склады торговли $\mathrm{F}_{13}$ & \\
\hline $\mathrm{F}_{3}$ & $\mathbf{F}_{4}$ \\
\hline 1. Склады материалов $F_{31}$ & 1. Склады тарно-штучных грузов $\mathrm{F}_{41}$ \\
\hline 2. Склады сырья $\mathrm{F}_{32}$ & 2. Склады сыпучих грузов $\mathrm{F}_{42}$ \\
\hline 3. Склады тары $\mathrm{F}_{33}$ & 3. Склады жидких грузов $\mathrm{F}_{43}$ \\
\hline 4. Склады готовой продукции $\mathrm{F}_{34}$ & 4. Склады газообразных грузов $\mathrm{F}_{44}$ \\
\hline
\end{tabular}

В соответствии со вторым принципом классификации фасетную формулу можно дополнить следующими характеристиками деления:

число хранимых номенклатур $-\mathrm{S}_{1}$,

высота зоны хранения - $\mathrm{S}_{2}$;

степень механизации и автоматизации $-S_{3}$;

огнестойкость $-\mathrm{S}_{4}$;

тип здания $-\mathrm{S}_{5}$;

связь с внешней средой и производством (поставщиками и потребителями) - $\mathrm{S}_{6}$;

компоновка экспедиций и зоны хранения $-\mathrm{S}_{7}$;

способ хранения грузов $-\mathrm{S}_{8}$;

физическая форма поступления и отправки грузов - $\mathrm{S}_{9}$;

характер воздействующих грузопотоков $-\mathrm{S}_{10}$; 


\begin{tabular}{|c|c|}
\hline $\mathrm{S}_{1}$ & $\mathrm{~S}_{6}$ \\
\hline 1. Однономенклатурный склад $\mathrm{S}_{11}$ & 1. Связанные с внешней средой $\mathrm{S}_{61}$ \\
\hline 2. До $10 \mathrm{~S}_{12}$ & 2. Связанные с производством $\mathrm{S}_{62}$ \\
\hline 3. До $100 \mathrm{~S}_{13}$ & 3. Смешанные $S_{63}$ \\
\hline \multicolumn{2}{|l|}{ 4. До $1000 \mathrm{~S}_{14}$} \\
\hline \multicolumn{2}{|l|}{ 5. До $10000 \mathrm{~S}_{15}$} \\
\hline \multicolumn{2}{|l|}{ 6. Свыше $10000 \mathrm{~S}_{16}$} \\
\hline 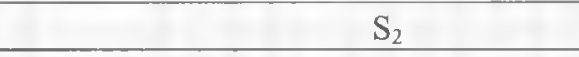 & $\mathrm{S}_{7}$ \\
\hline 1. До 3 м S & $\begin{array}{l}\text { 1. С раздельными приемной и отпускной } \\
\text { экспедициями } \mathrm{S}_{71}\end{array}$ \\
\hline 2. До $5 \mathrm{M} \mathrm{S}_{22}$ & 2. C совмещенными экспедициями $\mathrm{S}_{72}$ \\
\hline 3. До $10 \mathrm{~m} \mathrm{~S}_{23}$ & \\
\hline 4. До 15 м $S_{24}$ & \\
\hline \multicolumn{2}{|l|}{ 5. До $20 \mathrm{~m} \mathrm{~S} 25$} \\
\hline \multicolumn{2}{|l|}{ 6. Свыше 20 м S $_{26}$} \\
\hline $\mathrm{S}_{3}$ & $\mathrm{~S}_{8}$ \\
\hline 1. Немеханизированный склад $\mathrm{S}_{31}$ & 1. Навалом $\mathrm{S}_{81}$ \\
\hline 2. Механизированный склад $\mathrm{S}_{32}$ & 2. Штабелями $\mathrm{S}_{82}$ \\
\hline 3. Автоматизированный склад $\mathrm{S}_{33}$ & 3. С использованием стеллажей $\mathrm{S}_{83}$ \\
\hline 4. Автоматический склад $S_{34}$ & 4. Смешанные $\mathrm{S}_{84}$ \\
\hline $\mathrm{S}_{4}$ & (1) \\
\hline 1. Сгораемые $\mathrm{S}_{41}$ & 1. Навалом $\mathrm{S}_{91}$ \\
\hline 2. Трудносгораемые $\mathrm{S}_{42}$ & 2. Пакеты на подлонах $S_{92}$ \\
\hline 3. Несгораемые $\mathrm{S}_{43}$ & 3. Контейнеры $S_{93}$ \\
\hline 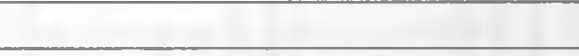 & 4. Смешанные $\mathrm{S}_{94}$ \\
\hline $\mathrm{S}_{5}$ & $\mathrm{~S}_{10}$ \\
\hline 1. Закрытые склады $S_{51}$ & 1. Детерминированные $S_{101}$ \\
\hline 2. Полузакрытые склады (навесы) $S_{52}$ & 2. Случайные (стохастические) $\mathrm{S}_{102}$ \\
\hline \multirow[t]{4}{*}{ 3. Открытые склады (плошадки) $\mathrm{S}_{53}$} & 3. Смешанные $\mathrm{S}_{103}$ \\
\hline & 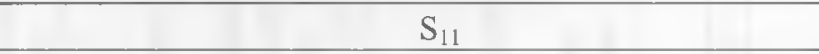 \\
\hline & 1. Однофазные $\mathrm{S}_{111}$ \\
\hline & 2. Многофазные $\mathrm{S}_{112}$ \\
\hline
\end{tabular}

Принятый метод классификации позволяет обеспечить более строгий подход к опознанию объекта. Классифицируемое множество складских систем может быть представлено в следующем виде:

$$
\left\{\mathrm{F}_{1 \mathrm{i}}, \mathrm{F}_{2 \mathrm{i}}, \ldots, \mathrm{F}_{4 \mathrm{i}} ; \mathrm{S}_{1 \mathrm{j}}, \mathrm{S}_{2 \mathrm{j}}, \ldots, \mathrm{S}_{11 \mathrm{j}}\right\} \quad \mathrm{j}=1,2, \ldots, \mathrm{k} ;
$$

где $\mathrm{F}_{14} \mathrm{~F}_{2 \downarrow} \mathrm{F}_{4 \mathrm{i}}$ - функциональные классификационные признаки, характеризующие подразделение признака на $\mathrm{i}$ - элементов;

$\mathrm{S}_{\mathrm{I}}, \mathrm{S}_{21}, \ldots, \mathrm{S}_{\mathrm{Ilj}}$ - структурные классификационные признаки, характеризующие подразделение признака на $\mathrm{j}$ - элементов. Такой подход к классификации складских систем позволяет обеспечить методологическое единство классификации и анализа ТСС. Причем можно пользоваться в зависимости от глубины сравнения и анализа полным или усеченным множеством признаков. Например, следующий набор классификационных признаков и их подразделений составляет:

$$
\left\{\mathrm{F}_{11}, \mathrm{~F}_{210}, \mathrm{~F}_{34}, \mathrm{~F}_{41} ; \mathrm{S}_{13}, \mathrm{~S}_{22}, \mathrm{~S}_{32}\right\}
$$

и характеризуют производственный склад предприятия перерабатывающей отрасли Агропрома, склад готовой продукции, тарно-штучных грузов, с числом хранимых номенклатур до 100, с высотой хранения 5 м, механизированный.

Для выбора инвестиционного проекта склада следует рассмотреть сушествующие, а также перспективные варианты объектов складского хозяйства с учетом современных тенденций развития техники и организации складирования. Количество возможных вариантов технологических решений по складам может быть большим, и выбор наиболее эффективных решений нуждается в тщательном анализе и учете всех факторов. 
Таб์รиนа 1

\begin{tabular}{|c|c|c|c|c|c|c|}
\hline \multirow{2}{*}{$\begin{array}{l}\text { № } \\
\text { варнан- } \\
\text { та }\end{array}$} & \multirow{2}{*}{$\begin{array}{l}\text { Способ } \\
\text { хранения }\end{array}$} & \multicolumn{3}{|c|}{ Особенности вариантов } & \multirow[t]{2}{*}{ Преимушества } & \multirow[t]{2}{*}{ Недостатки } \\
\hline & & Приемная экспедиция & Зона хранения & $\begin{array}{l}\text { Отпускная } \\
\text { экспедиция } \\
\end{array}$ & & \\
\hline 1 & \begin{tabular}{|l|} 
Блочный \\
напольный с \\
отдельными \\
экспедициями
\end{tabular} & $\begin{array}{l}\text { Применение } \\
\text { погрузчиков при } \\
\text { разгрузке гранспорта и } \\
\text { перемещении грузов }\end{array}$ & $\begin{array}{l}\text { Высота сооружения бм. } \\
\text { Размешение пакетов на } \\
\text { хранение и удаление } \\
\text { проводится погрузчиком }\end{array}$ & $\begin{array}{l}\text { Использование } \\
\text { погрузчиков при } \\
\text { компіектовании и } \\
\text { загрузке партий } \\
\text { стеклотары на } \\
\text { трапспорт }\end{array}$ & 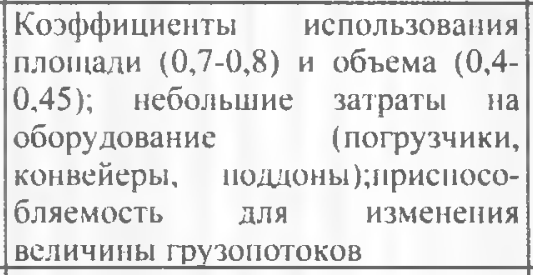 & $\begin{array}{l}\text { Олраничениая высота } \\
\text { штабелей; значительные } \\
\text { площади заняты под проходы } \\
\text { и проезды; сложность доступа } \\
\text { к каждой грузовой ццинице } \\
\text { пакета; сложность применения } \\
\text { средств автоматизации }\end{array}$ \\
\hline 2 & $\begin{array}{l}\text { Линейный } \\
\text { стеллажный с } \\
\text { отдельными } \\
\text { экспедициями }\end{array}$ & $\begin{array}{l}\text { Нспользование кранов- } \\
\text { штабелеров при } \\
\text { разгрузке транспорта; } \\
\text { перемещения тары с } \\
\text { помошью конвейеров } \\
\text { (роликовые, } \\
\text { колясочныс, } \\
\text { ленточные) }\end{array}$ & 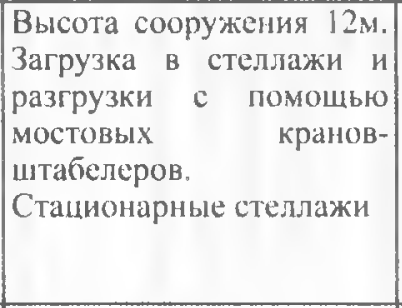 & \begin{tabular}{|l|} 
Комплектование \\
осуществляется \\
погрузчиками, отпуск \\
с помошью кранов- \\
штабелеров
\end{tabular} & $\begin{array}{l}\text { Коэффициент использования } \\
\text { площади (0,75-0,85) и объема } \\
(0,6-0,7) \text {; слаженная организация } \\
\text { двнжения грузопотоков в связи с } \\
\text { прямоточным движением; } \\
\text { свободный доступ к грузу, } \\
\text { возможность автоматизации }\end{array}$ & $\begin{array}{l}\text { Наличие порожних пробегов } \\
\text { оборудование в зонс хранения } \\
\text { в виду раздельных экспедиций } \\
\text { по приему и отпуску } \\
\end{array}$ \\
\hline 3 & $\begin{array}{l}\text { Блочный, } \\
\text { стеллажный с } \\
\text { отдельными } \\
\text { экспедициями }\end{array}$ & $\begin{array}{l}\text { Использование } \\
\text { погрузчнков при } \\
\text { разгрузке транспорта; } \\
\text { переменения пакетов с } \\
\text { помощью конвейеров }\end{array}$ & $\begin{array}{l}\text { Высота сооружения до } \\
12 \mathrm{M.} \mathrm{Загрузка} \mathrm{и} \mathrm{разгрузка} \\
\text { с помощью погрузчиков; } \\
\text { стеллажи передвижные } \\
\end{array}$ & $\begin{array}{l}\text { Применение } \\
\text { погрузчиков при } \\
\text { комплектации и } \\
\text { отпуске стеклотары } \\
\text { потребителю. } \\
\text { Транспортировка } \\
\text { конвейерами. } \\
\end{array}$ & $\begin{array}{lr}\text { Сочетание } & \text { преимуцества } \\
\text { стеллажного способа хранения } \\
\text { (свободный доступ к грузу) н } \\
\text { блочного } \\
\text { нспользования площади }(0,6-0,8) \text { і } \\
\text { объема }(0,5-0,6))\end{array}$ & $\begin{array}{l}\text { Возможность работы в проезде } \\
\text { одного погрузчика, что } \\
\text { ограничивает } \\
\text { производительность }\end{array}$ \\
\hline 4 & $\begin{array}{l}\text { Блочный, } \\
\text { стеллажный с } \\
\text { отдельными } \\
\text { экспедициями }\end{array}$ & $\begin{array}{l}\text { Выгрузка транспорта и } \\
\text { перемещения с } \\
\text { помощью погрузчиков }\end{array}$ & \begin{tabular}{|l|} 
Высота сооружения 12- \\
І6м; гравитацнонные \\
стеллажи. Загрузка ячеек \\
и извлечение при \\
помощи погрузчнков, \\
кранов-штабелеров и \\
специальных устройств
\end{tabular} & \begin{tabular}{|l|} 
Комплектование и \\
отпуск стеклотары \\
потребителю при \\
помощи погрузчиков
\end{tabular} & $\begin{array}{|lr|}\text { Высокие } & \text { козффициенты } \\
\text { использования плоцади }(0,8-0,9) \\
\text { и объсма }(0,75-0,85) ; & \text { слаженная } \\
\text { организация } & \text { движения } \\
\text { грузопотоков } \text { в } & \text { связи в } \\
\text { прямоточным } & \text { характером } \\
\text { перемещения; } & \text { возможность } \\
\text { автоматизация } & \\
\end{array}$ & $\begin{array}{l}\text { Необходнмость загрузки ячеек } \\
\text { и участков стеллажей пакетами } \\
\text { одного типоразмера } \\
\text { стеклотары; вероятность } \\
\text { неполного использования } \\
\text { обьема в связи с отсутствием } \\
\text { соответствующей стеклотары }\end{array}$ \\
\hline 5 & $\begin{array}{l}\text { Линейный } \\
\text { стеллажный со } \\
\text { смешенными } \\
\text { экспеднциями }\end{array}$ & $\begin{array}{l}\text { Нспользование } \\
\text { погрузчнков при } \\
\text { разгрузке трансиорта и } \\
\text { перемешении грузов }\end{array}$ & $\begin{array}{l}\text { Высота сооружения 12- } \\
\text { 16м; тупиковые } \\
\text { стеллажи. Зачрузка и } \\
\text { разгрузка ячеек } \\
\text { стеллажей с помощью } \\
\text { кранов-штабелеров, } \\
\text { стационарные стеллажи }\end{array}$ & $\begin{array}{l}\text { Комплектование и } \\
\text { отпуск стеклотары } \\
\text { при помощи } \\
\text { погрузчнков }\end{array}$ & \begin{tabular}{|l} 
Коэффициент ислользования \\
площади (0,8-0,85) и объема \\
$(0,65-0.75) ;$ отсутствия порожних \\
пробегов оборудования \\
(погрузчнков, \\
штабелеров), свободный доступ к \\
каждому грузу.
\end{tabular} & $\begin{array}{l}\text { Смешение потоков тары и } \\
\text { заявок на отпуск потребителю } \\
\text { в связи с совмешением } \\
\text { экспедиций } \\
\end{array}$ \\
\hline
\end{tabular}


В табл. 1 представлено Іить вариантов хранения тарно-штучных грузов на складах перерабатывающих предприятий агропромышленного комплекса. В основе вариантов лежат: пакетная форма грузообработки и два метода складирования - напольный и стеллажный.

Несмотря на то, что складирование грузов на перерабатывающих предприятиях осуществляется, как правило, с использованием первого метода, отображенного в варианте 1, в основе других вариантов (2-5) лежит более прогрессивный метод - с использованием стеллажей. При стеллажном способе в зависимости от использованного оборудования (электроштабелеры, автоматические краны-штабелеры и т. д.) хранение грузоединиц предусматривается на стеллажах разной конструкции: стационарных (варианты 2 и 5), передвижных (вариант 3) и гравитационных (вариант 4).

Размещение пакетов с грузом в ячейках стеллажей и последующее извлечение осуществляют в вариантах 2 и 5 с помошью автоматических кранов-штабелеров, которые управляются центральным компьютером или бортовым микропроцессором, в варианте 3 - с помощью электроштабелера с высотой подъема вил 4-5 м; вариант 4 для проведения этой операции предусматривает использование электроштабелеров или специальных грузовых устройств. С целью свободного доступа погрузо-разгрузочного оборудования к ячейкам стеллажи в вариантах 2,3,5 формируют по принципу (два стеллажа - проход). Также представляют собой интерес гравитационные стеллажи для хранения однотипных штучных грузов в случае больших грузопотоков и значительном обороте. Размещение грузоединип на хранение и извлечение осуществляется по принципу "первым вошел - первым вышел". Контейнер перемешается под действием силы тяжести в направлении от приемной к отпускной экспедиции. Недостатком таких систем является невозможность выдачи любого груза, а только крайнего в ячейке.

Длина (глубина) стеллажей может быть 30 м, однако оптимальное значение, как показали исследования УкрНИИпромсооружений, лежит в интервале 15-20 м; наклон стеллажей для деревянных поддонов составляет $4-5,5^{\circ}$. Степень использования объема зоны хранения в варианте с гравитационными стеллажами равен 75-85\%.

Второй тип хранения продукции - передвижные стеллажи дает то преимущество, что позволяет увеличить вместимость хранилища в результате возможности их перемещения. Однако опыт эксплуатации таких систем с передвижными стеллажами в стране невелик.

Выбор рационального варианта склада следует проводить стоимостным методом. Действительная стоимость инвестиционного проекта склада определяется на основе дисконтирования будущей стоимости [2]. А выбор рационального варианта склада следует проводить по критерию минимальных инвестиционных потребностей проекта, таким образом наибольшего внимания заслуживает вариант, который нуждается в минимальном объеме инвестиций.

Как отмечалось ранее, вариант 1 характеризуется напольным способом хранения и использованием традиционных подходов в управлении поточно-транспортной системой склада. С учетом перспективы автоматизации складских работ, компьютеризации управления и сокращения времени обработки груза обратимся к вариантам 2-5, среди которых заслуживает внимания вариант 4 с гравитационными стеллажами в зоне хранения

Источником финансовых ресурсов являются:

- собственные финансовые средства;

- заемные финансовые средства;

- финансовые средства, полученные от продажи акций;

- паевые и другие взносы членов трудовых коллективов, юридических лиц;

- средства государственного бюджета;

- средства внебюджетных фондов.

Табјища 2 Расчет объема инвестиний по нариантам, тыс. дол.

\begin{tabular}{|c|c|c|c|c|c|}
\hline \multirow{2}{*}{ Инвестиционные потребности } & \multicolumn{5}{|c|}{ Варианты } \\
\hline & I & II & III & IV & V \\
\hline 1. Строительство (реконструкция) & 420,0 & 560,0 & 560,0 & 560,0 & 560,0 \\
\hline $\begin{array}{l}\text { 2. ПГодъемно-транспортные механизмы " } \\
\text { оборудование }\end{array}$ & 80,0 & 270,0 & 270,0 & 240,0 & 270,0 \\
\hline 3. Монтаж оборудования & 8,0 & 17,0 & 17,0 & 17,0 & 17,0 \\
\hline 4. Лицензии и технологии & 10,0 & 24.0 & 24,0 & 24.0 & 24,0 \\
\hline 5. Проектныс работы & 18,0 & 30.0 & 30,0 & 30.0 & 30.0 \\
\hline 6. Обучение персонала & 25,0 & 40,0 & 40,0 & 40,0 & 40,0 \\
\hline 7. Вложения в оборотные средства & 60,0 & 90,0 & 90,0 & 90,0 & 90,0 \\
\hline 8. Сопутствуюшие расходы & 40,0 & 40,0 & 40,0 & 40,0 & 40,0 \\
\hline 9. Непредвнденные расходы & 12,0 & 12,0 & 12,0 & 12,0 & 12,0 \\
\hline 10. Обший объем инвестиций & 673,0 & 1083,0 & 1083,0 & 1053,0 & 1083,0 \\
\hline
\end{tabular}


Традиционными инструментами заемно о финансирования ныстушыю): :олгосрочныї банковский кре;ит,

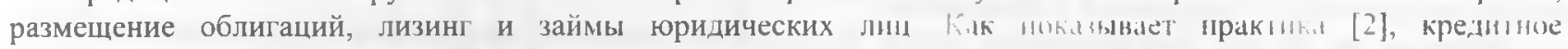
финансированне более выгодно для предпрнятий, чем финанырованис із виде собствснных фынансиых средств. Это объясняется тем, что процентные платежи за пользиание крелигом отчисляются до палюгов, т.е. включаются в валовые расходы, в то время как дивиденды вынланиваюлся и' 'льтой прибғли, которая остас'ся в распоряжении предприятия. Этот эффект носит название эффскта налюовой эконом!1! 13 го же время кредитное финансирование ция вредприятия является более рискованиым, поскольку прищни за кредил и

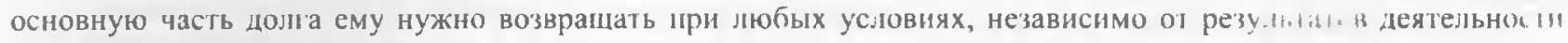
Эффективность инвестиционных проектов характеризуется системой показателей, в оснонь Расчета которьх лежит показатель чистого денежного потока.

Чистым денежным потоком называется разность между притоком и оттоком денежных средств, вложенных в погрузо-разгрузочные, транспортные и складские работы в каждом периоде осуществления проекта.

Использование данного подхода в классификации и определении действительной стонмосы инвестиционного проекта позвољяет делать минимальные затраты ири выборе варианта автоматизированной ТСС и ее дальнейшей эксплуатации.

\title{
Литература
}

1. Жуковський Э.И., Скорописов Ю.И. Совершенствование складських систем. - К.: Техн1ка, 19\$ 1.-142 с.

2. Фатхутдинов Р.А. Инновационный менеджмент: Учебник для вузов. 5-е узд. - СПб.: Питер, 2005.-4 18 с.

\section{АВТОМАТИЗАЦИЯ ПРОЦЕССА ПАСТЕРИЗАЦИИ МОЛОКА. ХАРАКТЕРНЫЕ ОСОБЕННОСТИ. ПРОБЛЕМЫ И ПРЕДЛОЖЕНИЯ.}

\author{
Баландин А., ст-нт \\ Одесская национальная академия пищевых технологий, Одесса
}

В статье описаны основные проблемы автоматизации производства пастеризованного молока в Украине. Перечислены показатели качества, которые нуждаются в улучиении для повышения качества продукиии. Обозначено направление для улучиения качества регулирования технологическим процессом и высказаны предложения по совериенствованию систем автоматического управления. ІІредстав.тен предложения для совериенствовиния уиравления производственны.и предприятием в целом.

This article dexcribes the main problems of aurom.tion of pastenrized milk in Ukraine. Listed quality indicatur., which need to he improwed to enhance the quality of products. The direction to improve the quality of management techniques is shown in this article. There are also suggestions to improve the automatic control systems, the proposals for improving the management of industrial enterprise as a whole.

Ключевые слова: молоко, пастеризация молока, пастеризационно-охладительные установки, технологический ІІроцесс, система автоматического регулиривания (САР), контур регулирования, параметрические возмущения, промышленный комплекс.

Пастеризация молока - важная отрасль пищевой громышленности. Молочные продукты необходимы человеку. В них содержатся белки, жиры, углеводы, аминокислоты, а также огромное количество витаминов и микроэлементов. Эти факторы порождают спрос на продукцию молочной громышленности. Для длительного хранения молока и молокопродуктов сырье подлается тепловой обработке, носящей название «пастеризация». Џель этой обработки - уничтожение вредных видов микроорганизмов и, как следствие, повышение срока хранения молока и устранение риска передачи инфекционных заболеваний

В современной молочной промышленности на территории Украины имеет промышленное значение лишь коровъе молоко. Молоко после дойки имеет температуру тела коровы, т.е. около $37^{\circ} \mathrm{C}$. После транспортировки на завод, в зависимости от времени года, температура охлаждается до $20-30^{\circ} \mathrm{C}$. На заводе молокю ихлаждае гя до $15^{\circ} \mathrm{C}$ и подается на пастеризацию.

На молокозаводах стараются минимизировать физический труд людей и ограничить человеческий фактор в управлении технологическим процессом. С этой целью процесс, по возможности, механизируют и автоматизируют. Современные пастеризационно-охладительные установки пластинчатого типа механизированы полностью и, принимая на входе сырье, на выходе выдают липи, конечный пролукг. Однако автоматизация этого процесса в Укранне и странах СІГ пока не решает все насущные проблемы управления пастеризащией молока. 